\title{
The human epidermal receptors in gastric cancer: molecular alterations and its role as therapeutic targets
}

\author{
Andrea Rebeca Bustos-Carpinteyro ${ }^{1,2}$, María Teresa Magaña-Torres ${ }^{1}$, Juan Ramón González-García1, \\ Juan Heriberto Torres-Jasso ${ }^{3}$ and Josefina Yoaly Sánchez-López ${ }^{1}$ \\ ${ }^{1}$ Division of Genetics, Biomedical Research Center of the West, Instituto Mexicano del Seguro Social; ${ }^{2} H u m a n$ Genetics Doctorate Program, \\ University Center of Health Sciences, Universidad de Guadalajara. Guadalajara, Jal.; ${ }^{3}$ Department of Biological Sciences, Division of Biological \\ Sciences and Health, University Center of the Coast, Universidad de Guadalajara, Delegación Ixtapa, Puerto Vallarta, Jal. Mexico
}

\begin{abstract}
Gastric cancer (GC) is the third leading cause of cancer death worldwide; both environmental and genetic factors are involved in the etiology of this neoplasia. The human epidermal receptor (HER) pathway is essential for proliferation and differentiation of normal cells; but it is also implicated in the growth of cancer cells. In this work we investigate the molecular alterations in genes that encodes for HER receptors reported in GC, as well the role as therapeutic targets. We reviewed the literature reported to date regarding overexpression of HER-receptors, amplification and somatic mutations in ERBB genes occurred in gastric tumors, as well as the anti-HER therapies tested for treatment of GC. In GC, the overexpression of HER family is reported in a range of $12-87 \%$ of cases; up to $67 \%$ of cases with amplification, and 90 somatic mutations in ERBB genes. The only drug anti-HER approved for using combined with chemotherapy, in treatment of patients with advanced GC is trastuzum$a b$; however, other targeted therapies are being investigated. The role of the HER family as a therapeutic target has not shown significant improvements in recent years; hence, further studies are required to find better options for treatment of GC.
\end{abstract}

KEY WORDS: Cell proliferation. Gene amplification. ERBB genes. Signal transduction. Stomach neoplasms.

\section{Introduction}

Globally, gastric cancer (GC) is the fifth most common type of cancer and the third cause of cancer-related death'. Several cancer-related signaling pathways are activated in GC. The human epidermal receptor (HER) pathway is one of the most important signal-transduction pathways implicated in tumor growth and differentiation in different types of cancer, including $\mathrm{GC}^{2}$.

The HER family is a group of four tyrosine kinase transmembrane proteins: HER1 (EGFR or ERBB1), HER2 (NEU or p185 ${ }^{\text {HER2}}$ ), HER3 and HER4. The HER family plays an important role in cell proliferation, differentiation and migration in normal cells, as well as in invasion, angiogenesis, metastasis and apoptosis in tumor cells ${ }^{3}$ (Fig. 1).

Three pathways are recognized in HER signaling: phosphatidyiinositol 3-kinase (PI3K)/AKT (PKB), RAS/ RAF/MEK/ERK1/2 and phospholipase C (PLCg) ${ }^{3,4}$. The PI3K/AKT pathway plays an important role in cell survival mediation, whereas RAS/ERK $1 / 2$ and the PLCg pathways participate in cell proliferation.

\section{Molecular alterations in the HER family}

\section{Overexpression}

Immunoreactivity for HER overexpression is categorized as $0<10 \%$ of cells with weak membrane

\author{
Correspondence: \\ Josefina Yoaly Sánchez-López \\ Sierra Mojada, 800 \\ Col. Independencia \\ C.P. 44340 , Guadalajara, Jal., México \\ E-mail: yosalo1795@yahoo.com
}

Date of reception: 08-11-2016

Date of acceptance: 01-12-2016

DOI://dx.doi.org/10.24875/GMM.M18000090
Gac Med Mex. 2017;153:752-762

Contents available at PubMed www.gacetamedicademexico.com 


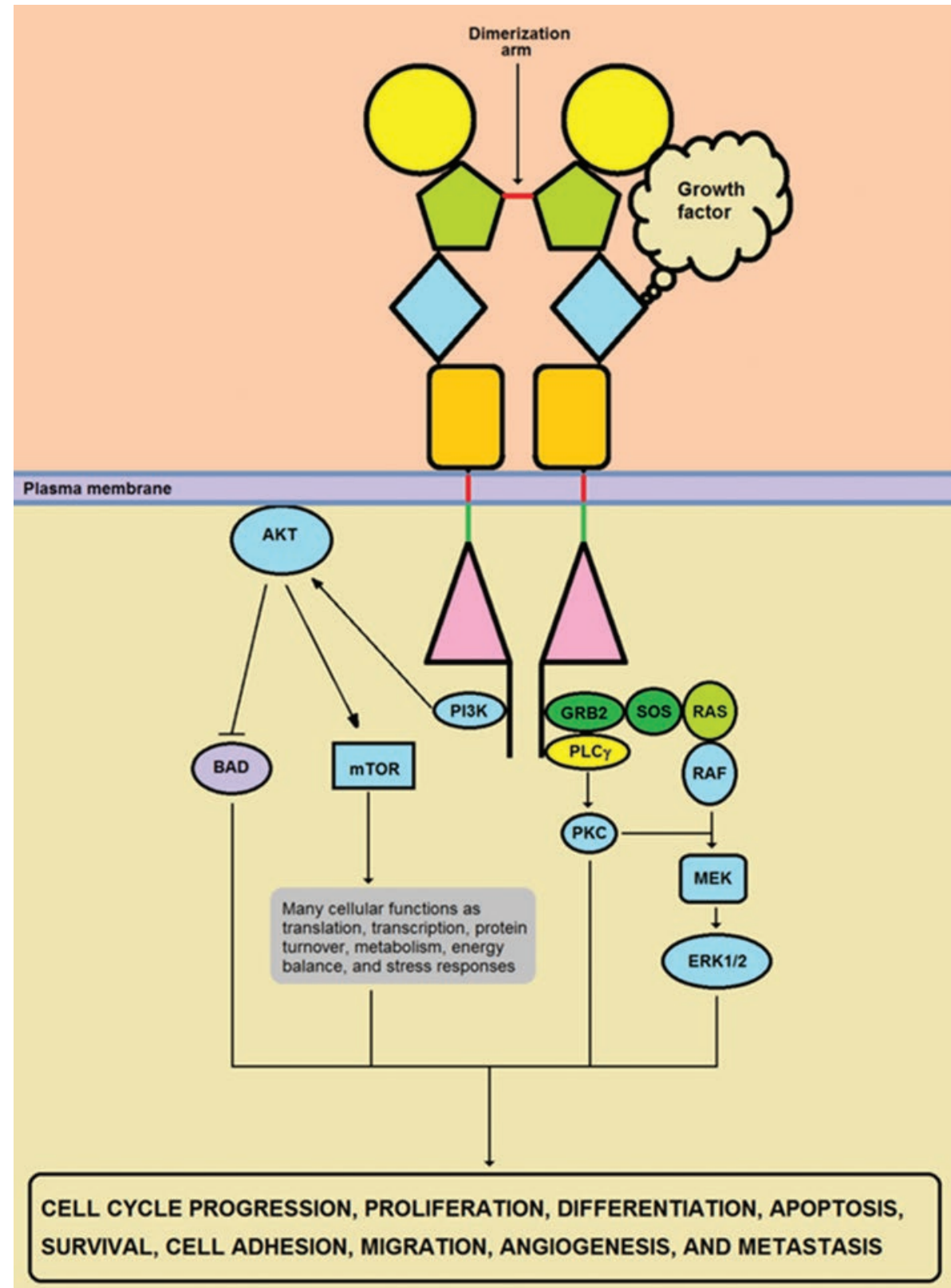

Figure 1. General diagram of the dimerization process and the main signaling pathways of the HER receptor family. Binding to the ligand affects the I and III domains (except for HER2).

reactivity), $1+(>10 \%$ of cells with partial and weak membrane activity), $2+(>10 \%$ of tumor cells with mild to moderate activity at the basolateral or complete membrane). Gastric tumors with an IHC 3+ classification are considered to be HER-positive (overexpression); in contrast, samples with IHC 2+ must be evaluated with in situ hybridization in order to establish the HER expression status ${ }^{5}$.

HER1 overexpression in gastric tumors broadly varies $(2-63 \% \text { of cases })^{6-8}$. HER1 overexpression is mainly localized in the cytoplasm ( $45 \%$ of cases), while only in $9 \%$ it exhibits membrane expression ${ }^{7-9}$ and is not found in the nucleus. Overexpression has been associated with old age, a more aggressive course of the disease (poor differentiation, diffuse type and infiltrating capacity), proximal localization and advanced stage of disease ${ }^{6}$; however the prognostic role of HER1 overexpression in GC is not clear since, in some studies, HER 1 positivity was significantly associated with poor prognosis ${ }^{10,11}$, whereas other authors failed to demonstrate a significant correlation between these factors ${ }^{7,12,13}$. 
HER2 overexpression also broadly varies in GC (from 4.4 to $53.4 \%$ of cases) ${ }^{14}$. Overexpression is more common in the cytoplasm (62\%) than in the membrane $(17 \%)$, and is also more common in the intestinal $(32 \%)$ than in the diffuse subtype $(21 \%)^{6,14}$, as well as in older patients?.

HER3 is overexpressed in $87 \%$ of gastric tumors ${ }^{15}$, and is more common in the cytoplasm (64\%) than in the nucleus $(34 \%)$ or the membrane $(2 \%)^{6,7}$, although Choi et al..$^{15}$ observed that HER3 is mainly found in the nucleus. For some authors, HER 3 overexpression is associated with intestinal subtype $\mathrm{GC}^{6,7,16}$, while for others, it is related to the diffuse subtype ${ }^{17}$. On the other hand, a lack of association with any GC subtype has also been described ${ }^{18,19}$. In addition, overexpression is associated with well- and moderately-differentiated tumors, older age, greater tumor invasion, lymph node involvement, tumor metastasis and poor survival rate $e^{6,7,18}$. HER3 nuclear expression in GC is associated with vascular and lymphatic invasion, as well as with poor survival (HER3+ 24-38 months vs. HER3- 45-47 months) ${ }^{6,16}$.

HER4 expression appears to be higher in gastric tumor tissues than in adjacent gastric mucosa ${ }^{6}$. Overexpression is cytoplasmic in $23-24 \%$ of cases, membranous in $15-18 \%$ and nuclear in $2 \% 6,7$. HER4 overexpression is associated with tumor characteristics of good prognosis, such as intestinal subtype, good or moderate differentiation and no vascular, lymphatic or perineural invasion ${ }^{6}$. This is consistent with the role of HER4 in differentiation and antiproliferative response ${ }^{20}$. In spite of its alleged implication in a better prognosis in patients with GC, some reports have demonstrated that HER4 overexpression is associated with advanced stages of the diseas $\mathrm{e}^{16}$ and with the presence of signet-ring cells ${ }^{21}$.

\section{Amplification}

ERBB genes amplification is defined as positive when the HER: CEP signals ratio is $\geq 2$. Chromosome polysomy is defined as $\geq 3$ CEP signals on average per cell. In the fluorescent or chromogenic in situ hybridization-based analysis, a dual coloration system is used, with the probe for any of the EGFR, ERBB2, ERBB3 or ERBB4 and with the respective chromosome-specific centromeric probe (CEP). EGFR gene amplification has been identified in $2-29 \%^{22-25}$ of GC cases, and chromosome 7 polysomy, in $3-10 \%$ of cases. ERBB2 amplification is reported in 8 to $22.1 \%$ of gastric tumors ${ }^{5,6,22,26-30}$, and is associated with the intestine al subtype, with well- or moderately-differentiated gastric tumors, and with reduced survival (17 months for HER2+ vs 40 months for HER2-) ${ }^{6}$. ERBB3 amplification has not yet been observed in $\mathrm{GC}^{6}$. ERBB4 in GC was reported by Nielsen et al. ${ }^{20}$ in $67 \%$ of cases, but Begnami et al. ${ }^{6}$ did not observe ERBB4 gene amplification, which denotes the heterogeneity between gastric tumors.

\section{Mutations in genes that encode the HER family}

The analysis of mutations in the HER family genes has been carried out more frequently in the tyrosine kinase domain than in other domains ${ }^{23,31-37}$. Mutations have not been detected in all studies, in part due to the analyzed tumor (diffuse or intestinal), tumor status, and even due to ethnic differences ${ }^{33,34,38-42}$.

In GC, at least 90 somatic non-synonym mutations have been reported in ERBB genes, out of which 86 are missense, three are nonsense mutations and one is the deletion of an entire codon (Table 1).

The distribution of these mutations in each $E R B B$ gene is: 19 in EGFR, 34 in ERBB2, 20 in ERBB3 and 17 in ERBB4. These mutations affect all domains of the receptor, although more frequently the tyrosine kinase domain (27/90, 30.0\%) (Fig. 2). Holbrook et al..$^{43}$ identified $50 \%$ (44/88) of these mutations and determined their possible functional impact; furthermore, they predicted that 28 of them can have an important role in the development or progression of cancer (Table 1).

\section{Mutations in the EGFR gene}

Mutations in the EGFR gene in GC are rare or absent, according to most reports. Their incidence varies in different studies from $0 \%{ }^{33,38-41}$, to $5.1 \%^{31,32}$ and up to $30^{43}$. Nineteen different somatic mutations have been observed (17 missense and two nonsense), mainly occurring in the tyrosine kinase domain (7/19) and domain II (5/19) (Fig. 2 and Table 1). Some recurrent somatic mutations were observed in two or more cases of GC: V308A, V505G and Y1016S. Moutinho et al. ${ }^{23}$ carried out an analysis of the correlation between alterations in the EGFR gene and clinical characteristics, and suggested that $E G F R$ is implicated in tumor size and progression regulation. Activating mutations in EGFR are not frequent in GC, but other alterations, such as mutations or copy number variations, are implicated in an 
Table 1. Somatic mutations in ERBB family genes reported in gastric cancer

\begin{tabular}{|c|c|c|c|c|}
\hline \multirow{2}{*}{$\frac{\operatorname{EGFR}(\mathrm{n}=19)}{{ }^{c} \mathrm{~K} 189 \mathrm{~T}^{42}}$} & \multicolumn{2}{|c|}{ HER2 $(\mathrm{n}=34)$} & \multirow{2}{*}{$\frac{\text { HER3 }(\mathbf{n}=\mathbf{2 0})}{\text { f.j. }^{\prime} 104 M^{44}}$} & \multirow{2}{*}{$\frac{\text { HER4 }(\mathrm{n}=17)}{{ }^{n} \mathrm{~V} 59 \mathrm{D}^{42}}$} \\
\hline & e,il101V43 & ${ }^{\mathrm{d} D} 769 \mathrm{H}^{34}$ & & \\
\hline cW200X ${ }^{42}$ & ${ }^{\mathrm{e}} \mathrm{T} 216 \mathrm{P}^{43}$ & ${ }^{d} \mathrm{G} 776 \mathrm{~S}^{35}$ & YY111C 44 & h, L91P 43 \\
\hline${ }^{\mathrm{a}} \mathrm{C} 232 \mathrm{~S}^{43}$ & ${ }^{e} \mathrm{D} 234 \mathrm{~A}^{43}$ & dV777L 34 & ${ }^{\mathrm{f} R} 135 \mathrm{~L}^{44}$ & h.'V2261 43 \\
\hline aV308A $A^{43}$ & ${ }^{e} \mathrm{C} 235 S^{43}$ & ${ }^{\mathrm{d} Q 799 P}{ }^{34}$ & ${ }^{9} \mathrm{~A} 172 \mathrm{P}^{43}$ & 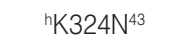 \\
\hline${ }^{a} \mathrm{R} 309 \mathrm{G}^{43}$ & e.iD277Y43 & dV842|33 & f.j. A232V ${ }^{44}$ & h,il329M ${ }^{43}$ \\
\hline${ }^{\mathrm{a}} \mathrm{C} 311 \mathrm{G}^{43}$ & eV296L ${ }^{43}$ & dT862A ${ }^{42}$ & f.jP262H 24 & $h_{i} i A 380 E^{43}$ \\
\hline av505G $\mathrm{G}^{43}$ & e. $\bigvee 308 G^{43}$ & dL869Q & ${ }^{f} \mathrm{G} 284 \mathrm{R}^{42}$ & h. $\mathrm{H} 505 \mathrm{P}^{43}$ \\
\hline 'T638M" 42 & ${ }^{d} S 310 F^{42}$ & EE914G ${ }^{43}$ & ${ }^{f} \mathrm{D} 297 Y^{43}$ & hW513G ${ }^{43}$ \\
\hline${ }^{b} \mathrm{C} 646 X^{43}$ & ${ }^{e} \mathrm{C} 331 \mathrm{G}^{43}$ & é994W³ & ${ }^{\mathrm{f}} \mathrm{E} 332 \mathrm{~K}^{42}$ & ${ }^{\mathrm{h}} \mathrm{A} 773 \mathrm{~S}^{37}$ \\
\hline${ }^{b} N 647 D^{43}$ & ${ }^{e} \mathrm{D} 417 \mathrm{H}^{43}$ & e:G995A & 'M406T44 & hL798R R2 $^{42}$ \\
\hline${ }^{\mathrm{c}} \mathrm{A} 767 \mathrm{~V}^{23}$ & ${ }^{e} \mathrm{D} 417 \mathrm{~A}^{43}$ & e. $\mathrm{Q} 1206 \mathrm{H}^{43}$ & ${ }^{\mathrm{f}} \mathrm{R} 453 \mathrm{H}^{44}$ & h.iK966T ${ }^{43}$ \\
\hline${ }^{\circ} \mathrm{C} 781 \mathrm{~S}^{32}$ & e, T526P ${ }^{43}$ & ${ }^{e} A 1216 D^{43}$ & ${ }^{f} R 475 W^{42}$ & ${ }^{h} F 974 V^{43}$ \\
\hline cY801C 31 & e.,N530T ${ }^{43}$ & ${ }^{e} F 1217 S^{43}$ & $\mathrm{fK}^{\mathrm{K}} 498 \mathrm{I}^{44}$ & ${ }^{h} F 1064 L^{42}$ \\
\hline${ }^{c} \mathrm{~N}_{842 D^{23}}$ & e. $L 637 V^{43}$ & ${ }^{\mathrm{e} F 1217 C^{43}}$ & V654G ${ }^{43}$ & ${ }^{h} E 1199 K^{42}$ \\
\hline${ }^{c} \mathrm{~V} 8433^{142}$ & ${ }^{e} \mathrm{C} 642 \mathrm{~S}^{43}$ & & f.j, $Q 809 R^{44}$ & ${ }^{h} E 1201 X^{43}$ \\
\hline cL858R ${ }^{31}$ & ${ }^{d} \mathrm{R} 678 Q^{42}$ & & fK926R ${ }^{43}$ & ${ }^{n} A 1233 G^{42}$ \\
\hline${ }^{c} G 863 D^{23}$ & dK724N34 & & ${ }^{\mathrm{f}} \mathrm{E} 928 \mathrm{G}^{36}$ & ${ }^{\mathrm{h}} \mathrm{R} 1250 \mathrm{Q}^{42}$ \\
\hline${ }^{c} Y 1016 S^{43}$ & dT733| ${ }^{34}$ & & fL930W43 & \\
\hline c. $V 1109 D^{43}$ & $\mathrm{~d} \mid 740 \mathrm{~T}^{42}$ & & 'R1089W'44 & \\
\hline & d,e L $755 S^{34,43}$ & & ${ }^{\mathrm{f}} 1218 \mathrm{delE}^{36}$ & \\
\hline
\end{tabular}

Number of sequences used to name each mutation: aHM_201282 (628 aa); bNM_201284 (705 aa); ' NM_0055228 (1210 aa); 'NM_004448 (1255 aa); 'mutations described by

Holbrook et al. ${ }^{43}$ considering the 1225 aa (NM_001005862) isoform were named by us according to isoform 1255 aa (NM_004448); 'NM_001982 (1342 aa); 9NM_001005915 (183 aa);

hNM_005235 (1308 aa); imutations with a SIFT score > 0.05: the amino acid change possibly does not significantly affect the protein function; 'evidence of wild-type HER2 oncogenic activity.

increase of diffuse tumors size; in addition, alterations in this gene have been suggested to confer an invasive behavior in neoplastic cells.

\section{ERBB2 gene mutations}

Only few studies have been conducted to identify ERBB2 somatic mutations in GC in comparison with lung and breast cancers. ERBB2 mutation rate in GC ranges from $2 \%{ }^{33-35}$ to $60 \%{ }^{43}$; however, of the $30 \mathrm{mu}$ tations detected by Holbrook et al. ${ }^{43}, 14$ seem to be of little importance for the development or progression of cancer, thus decreasing the frequency of ERBB2 mutations with tumoral impact to $32 \%$. So far, 34 ERBB2 different missense variants have been described, out of which 13 were detected in the tyrosine kinase domain ${ }^{33-35,42,43}$ (Fig. 2) and in advanced GC ${ }^{34}$. Similarly as observed for EGFR, most mutations in ERBB2 are heterogeneous in different types of tumors. Very few mutations are recurrent, such as D204A, L755S, R678Q and V777L, among oth$\mathrm{ers}^{34,42,43}$. Some mutations are observe in several patients with the same type of cancer and other in patients with different types of cancer. On the other hand, the same codon is changed by different amino acids, suggesting the presence of hot spots; for example, L755S/W/P, D769H/Y, G776S/L/V and V777L/ $\mathrm{M}^{34,35,45-47}$. The L755S mutation (called L725S by Holbrook et al. ${ }^{43}$ ) is one of the most frequently observed mutations in several types of cancer. The somatic mutations D769H, D769Y, V777L and V842I are activating mutations that can promote cell proliferation by themselves ${ }^{45}$.

\section{ERBB3 gene mutations}

The frequency of mutations in the ERBB3 gene in GC ranges from $0.6 \%{ }^{48}$ to $13 \%{ }^{44}$ Currently, at least 20 


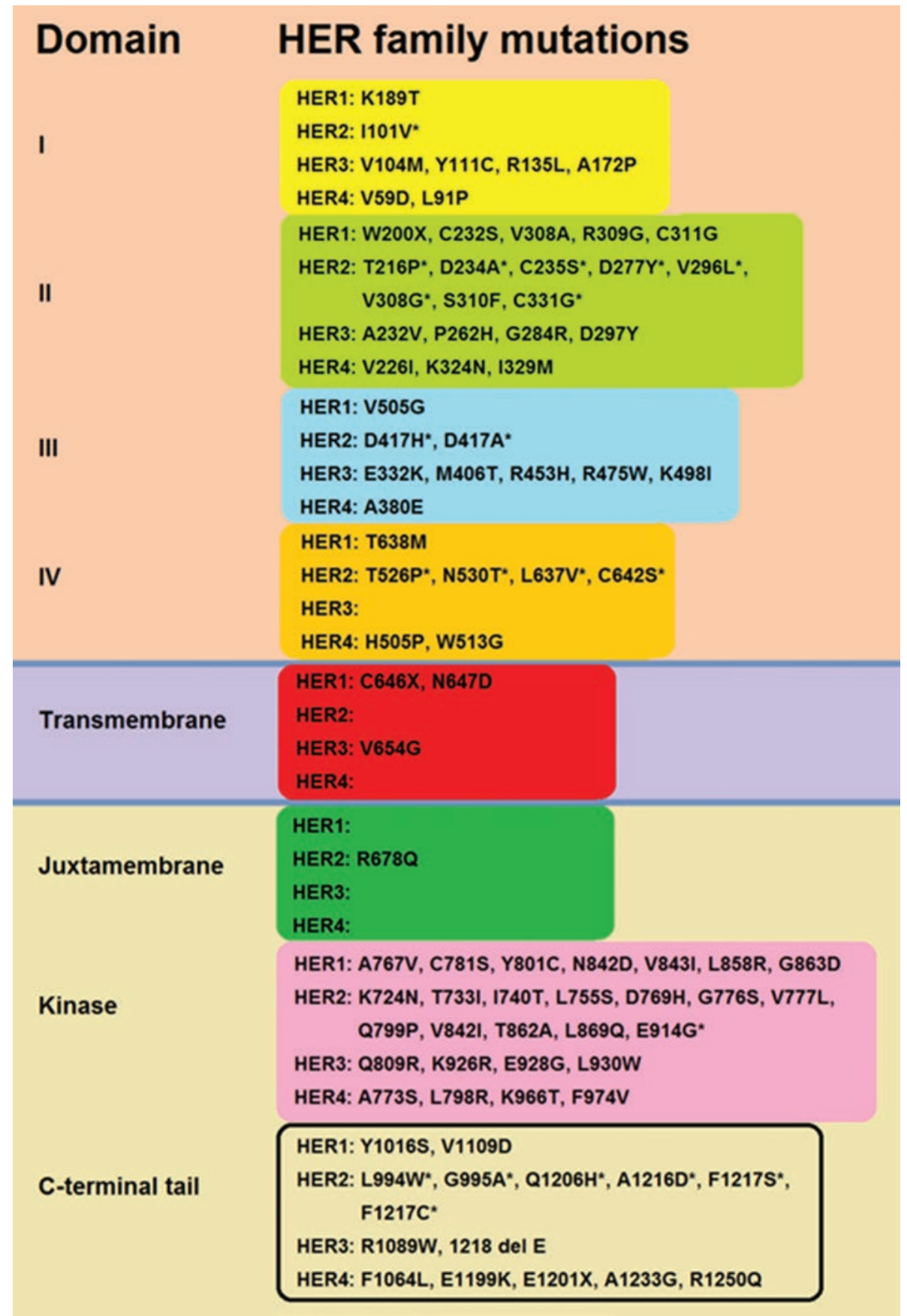

Figure 2. Localization of mutations reported to affect the ERRBB-HER receptor family in gastric cancer. Mutations marked with an asterisk were described by Holbrook et al. ${ }^{43}$ considering the 1225 amino acid (NM_001005862) isoform; we relocated them according to the 1255 amino acid (NM_004448) isoform.

somatic mutations in ERBB3 have already been identified (19 missense and one complete codon deletion). Unlike observations for EGFR and ERBB2, most mutations occur within domain III, which participates in the ligand binding ${ }^{36,42.43 .44}$ (Fig. 2). Jaiswal et al. ${ }^{44}$ analyzed the functional impact of four ERBB3 gene mutations (V104M, A232V, P262V, P262H and Q809R) and found evidence of oncogenic potential in all of them. On the other hand, Holbrook et $\mathrm{al}^{43}$ analyzed five mutations of the ERBB3 gene (A172P, D297Y, V654G, K926R and L930W) and found a possible clinical relevance for GC. Most these mutations have functional importance, as they affect interactions that are necessary for dimerization or ligand binding ${ }^{44}$. 


\section{Mutations in the ERBB4 gene}

The frequency of ERBB4 mutations in $\mathrm{GC}$ ranges from $0.6 \%^{37}$ to $28 \%{ }^{43}$. There are at least 17 different somatic mutations reported in GC (16 are missense and one nonsense). Mutations are distributed across the entire gene; however, a slight accumulation is observed at the C-terminal domain (Fig. 2 and Table 1). Although no functional characterization of ERBB4 gene mutations has been made in GC, Holbrook et al. $^{43}$ calculated the potential of 10 variants and found that at least 4 mutations (K324N, W513G, F974V and E1201X) can be clinically important for the development of cancer.

\section{Targeted therapies against the HER receptor family}

There are two classes of anti-HER therapy: monoclonal antibodies and small molecule tyrosine kinase inhibitors. Anti-HER monotherapy for GC is less toxic, but also less efficient, and combination of agents targeted against HER with traditional chemotherapeutic agents is therefore most commonly used.

\section{Monoclonal antibodies}

\section{Anti-HER1 therapies}

Cetuximab is a chimeric monoclonal antibody-type G1 immunoglobulin (IgG1) that binds to HER1 extracellular domain and competitively inhibits the binding to EGF ligand and other ligands, as well as ligand-induced tyrosine kinase phosphorylation. Cetuximab also induces EGFR internalization, downregulation and degradation $^{49}$. It was the first anti-EGFR antibody approved by the US Food and Drug Administration (FDA) for the treatment of squamous cell carcinoma and advanced wild-type KRAS colorectal cancer ${ }^{50,51}$. It is the most widely investigated anti-HER1 therapy in $\mathrm{GC}^{52-54}$. It hasn't had a significant impact on survival (3.116.6 months) or on progression-free survival (1.611 months) in patients with GC and gastroesophageal cancer (GEC) (Table 2); nevertheless, there is the registry of one patient with metastatic GC treated with cetuximab with the longest progression-free survival reported (7 years and 11 months) ${ }^{82}$.

Panitumumab is the first completely human IgG2 monoclonal antibody approved for the treatment of EGFR-expressing metastatic colorectal cancer, based on results that showed clinical benefits ${ }^{83}$. One phase III trial (REAL-3) assessed panitumumab in treatment-naive patients with advanced esophageal cancer and GC, but the results showed no survival increase $^{68}$ (Table 2). Other four clinical trials were discontinued owing to a lack of efficacy of panitumumab added to chemotherapy ${ }^{84}$. The failure of randomized phase III trials using cetuximab or panitumumab in combination with chemotherapy was due to the lack of selection of a specific patient population according to EGFR expression and to the negative interaction of the anti-EGFR monoclonal antibody and the therapeutic agent. More recent studies are assessing panitumumab efficacy in combination with other components ${ }^{84}$.

Matuzumab is a humanized IgG1 monoclonal antibody against HER1. In a randomized phase II trial conducted in patients with advanced GC with HER1 overexpression, matuzumab + epirubicin + cisplatin + capecitabine were evaluated as first-line therapy, and the results showed that the combination of matuzumab with chemotherapy does not improve survival rates (Table 2); therefore, matuzumab was not tested in phase III trials 69,85 .

Nimotuzumab is a humanized IgG1 that has demonstrated efficacy without serious skin toxicity as the one caused by other HER1-binding therapies; however, survival is similar to that observed with other drugs $^{70-72}$ (Table 2).

\section{Anti-HER2 therapies}

Trastuzumab is a humanized monoclonal antibody that binds to HER2 extracellular domain IV and prevents intracellular tyrosine kinase activation. It was approved for use in combination with chemotherapy as an adjuvant for patients with HER2+ breast cancer and for advanced GC therapy in HER2+ treatment naive patients in combination with chemotherapy. However, trastuzumab confers higher risk of cardiotoxicity ${ }^{86}$, which is partially reversible after the antibody is eliminated ${ }^{53,87}$. The only study that has demonstrated strong evidence for survival improvement was the phase III ToGA trial, which included patients with HER2+ GC (Table 2); patients with IHC $2+$ tumors and positive fluorescent in situ hybridization or IHC 3+ tumors had a marked survival improvement $(16.0 \text { months })^{30}$.

Pertuzumab is a humanized monoclonal antibody that binds to the HER2 dimerization domain II, unlike trastuzumab, which binds to domain IV. It inhibits 
Gaceta Médica de México. 2017;153

Table 2. HER-targeted therapies for patients with gastric cancer (studies with published results)

\begin{tabular}{|c|c|c|c|c|c|}
\hline Drug & Target & Combined with chemotherapy & PFS (months) & MS (months) & Reference \\
\hline \multicolumn{6}{|c|}{ Monoclonal antibodies } \\
\hline \multirow{14}{*}{$\begin{array}{l}\text { Cetuximab } \\
\text { HER1 }\end{array}$} & & Irinotecan, leucovorin, $5 \mathrm{FU}^{+}$ & $8-9$ & $16-16.6$ & Pinto, et al. ${ }^{55}$ \\
\hline & & & & & Kanzleer, et al..$^{56}$ \\
\hline & & & & & Moehler, et al..$^{57}$ \\
\hline & & Cisplatin, leucovorin, $5 \mathrm{FU}^{+}$ & 11 & 14.5 & Yeh, et al..$^{58}$ \\
\hline & & Oxaliplatin, capecitabine ${ }^{\dagger}$ & 6.5 & 11.8 & Kim, et al. ${ }^{52}$ \\
\hline & & Oxaliplatin, leucovorin, 5FU ${ }^{+}$ & 5.5 & 9.9 & Han, et al. ${ }^{59}$ \\
\hline & & Oxaliplatin, docetaxel ${ }^{\dagger}$ & 5.1 & 9.4 & Richards, et al. ${ }^{60}$ \\
\hline & & Cisplatin, docetaxel ${ }^{\dagger}$ & 5 & 9 & Pinto, et al. ${ }^{61}$ \\
\hline & & Capecitabine, cisplatin ${ }^{\dagger}$ & 4.4 & 9.4 & Lordick, et al. ${ }^{62}$ \\
\hline & & Irinotecan, leucovorin, 5FU‡ & 4.9 & 8.1 & $\mathrm{Li}$, et al. ${ }^{63}$ \\
\hline & & Irinotecan ${ }^{\ddagger}$ & 2.8 & 6.1 & Schonnemann, et al. ${ }^{64}$ \\
\hline & & $\begin{array}{l}\text { Irinotecan }{ }^{\ddagger} \\
\text { Irinotecan, leucovorin, 5FU } \\
\text { Irinotecan, cisplatin }{ }^{\ddagger} \\
\text { Oxaliplatin, leucovorin, 5FU } \\
\text { Docetaxel, cisplatin }{ }^{\ddagger}\end{array}$ & 1.7 & 3.2 & Park, et al. ${ }^{65}$ \\
\hline & & Docetaxel $\left.\right|^{\ddagger}$ & 2.1 & 5.4 & Tebbutt, et al. ${ }^{66}$ \\
\hline & & None $\ddagger$ & 1.6 & 3.1 & Chan, et al. ${ }^{67}$ \\
\hline Panitumumab & HER1 & Epirubicin, oxaliplatin, capecitabine ${ }^{\dagger}$ & 6 & 8.8 & Waddell, et al. ${ }^{68}$ \\
\hline Matuzumab & HER1 & Epirubicin, cisplatin, capecitabine ${ }^{\dagger}$ & 4.8 & 9.4 & Rao, et al. ${ }^{69}$ \\
\hline \multirow[t]{3}{*}{ Nimotuzumab } & HER1 & Cisplatin, $\mathrm{S}-1^{\dagger}$ & 5 & - & Wang, et al. ${ }^{70}$ \\
\hline & & Irinotecan ${ }^{\ddagger}$ & 2.4 & 8.3 & Satoh, et al..$^{71}$ \\
\hline & & Docetaxel, cisplatin, 5FU‡ & 6.5 & 12.5 & $\mathrm{Xu}$, et al. ${ }^{.2}$ \\
\hline $\begin{array}{l}\text { Trastuzumab } \\
\text { HER2 }\end{array}$ & & 5FU, capecitabine, cisplatin ${ }^{\dagger}$ & 6.7 & 13.8 & Bang, et al. ${ }^{29}$ \\
\hline \multicolumn{6}{|c|}{ Tyrosine kinase inhibitors } \\
\hline \multirow[t]{3}{*}{ Erlotinib } & HER1 & Alone $^{\dagger}$ & GC 1.6 & 3.5 & Dragovich, et al. ${ }^{73}$ \\
\hline & & & GEC 3 & 6.7 & \\
\hline & & Oxaliplatin, leucovorin, 5FU ${ }^{\dagger}$ & 5.5 & 11 & Wainberg, et al. ${ }^{74}$ \\
\hline \multirow[t]{2}{*}{ Gefitinib } & HER1 & Alone $^{\dagger}$ & - & 5.5 & Aldestein, et al. ${ }^{75}$ \\
\hline & & Cisplatin, 5FU, radiotherapy ${ }^{\dagger}$ & - & 24.2 & Rodriguez, et al. ${ }^{76}$ \\
\hline \multirow[t]{4}{*}{ Lapatinib } & HER1 & Alone $^{\dagger}$ & 2 & 4.8 & Iqbal, et al. ${ }^{77}$ \\
\hline & & Capecitabine ${ }^{\ddagger}$ & 1.6 & - & Lorenzen, et al. ${ }^{78}$ \\
\hline & & Capecitabine, oxaliplatin $^{\dagger}$ & 6 & 12.2 & Hecht, et al. ${ }^{79}$ \\
\hline & & Paclitaxel $^{\ddagger}$ & 5.4 & 11 & Satoh, et al. ${ }^{80}$ \\
\hline Dacomitinib & HER1,2,4 & Alone $^{\ddagger}$ & 2.1 & 7.1 & Lee, et al. ${ }^{81}$ \\
\hline
\end{tabular}

MS: mean survival; PFS: progression-free survival. t': first line treatment; ": second line treatment. 
HERR2 dimerization with other HER family members and exhibits antibody-dependent cell cytotoxicity (ADCC)-related anti-tumor activity ${ }^{88,89}$. The effect of adding pertuzumab to chemotherapy is currently being investigated ${ }^{84}$.

One meta-analysis suggested that anti-HER1 monoclonal antibodies-based therapies result in lower survival rates than anti-HER2 therapies. However, chemotherapy together with anti-HER2 targeted therapy significantly increases the risk of diarrhea, hypocalcemia, mucositis and rash in comparison with chemotherapy alone ${ }^{85}$.

Trastuzumab emtansine (T-DM1) is an antibody that combines trastuzumab and a maitansine-derived microtubule inhibitor (DM1). This drug combines two strategies: trastuzumab anti-HER2 activity and targeted intracellular DM1 delivery, which interferes with mitosis and promotes apoptosis. Its use in HER2+ breast cancer has already been approved ${ }^{90}$. Clinical trials are recruiting patients in order to assess T-DM1 together with chemotherapy in patients with $\mathrm{GC}^{84,88,91}$.

\section{Therapies against HER2-HER3 heterodimers}

MM-111 is a bispecific fusion antibody that comprises anti-HER2 and anti-HER3 antibodies bound by human serum albumin. MM-111 binds to HER2 and HER3-expressing cells and blocks ligand-induced signaling ${ }^{92}$.

\section{Tyrosine kinase inhibitors}

\section{HER1 inhibitors}

Erlotinib has been approved for the treatment of lung and pancreatic cancer ${ }^{54}$. In a phase II trial, erlotinib was found to be active in patients with gastroesophageal cancer, but good response was not obtained in patients with $\mathrm{GC}^{73}$ (Table 2). In a phase II trial, a combination of erlotinib, oxaliplatin, leucovorin and 5-fluorouracyl (5FU) was administered to treatment-naive patients with advanced or metastatic esophageal cancer and gastroesophageal cancer; the results were similar to those previously reported ${ }^{74}$ (Table 2).

Gefitinib was approved by the FDA for the treatment of advanced non-small cell lung cancer ${ }^{54}$. As monotherapy, it is associated to low survival ${ }^{75}$, but in combination with cisplatin, 5FU and radiotherapy, it has shown the highest survival rate (24.2 months) in esophageal and gastroesophageal cancer ${ }^{76}$ (Table 2).

Neratinib acts by covalently binding to a cysteine lateral chain in the HER receptor. It is directed to patients with activating mutations in the EGFR, ERBB2 or ERBB3 genes and to patients with EGFR amplification.

\section{HER1/HER2 inhibitors}

Lapatinib is an orally-active molecule for HER1 and HER2 double-inhibition that has been approved to be used in HER2+ breast cancer. It is an inhibitor more potent for HER1 and HER2 than for HER4 (> 10x) ${ }^{91}$. It obtained the best results in patients with advanced GC with paclitaxe ${ }^{71}$ and in combination with capecitabine and oxaliplatin ${ }^{79}$, in comparison with single-agent administration ${ }^{77}$ or in combination only with capecitabine $^{79}$ (Table 2).

Afatinib is an irreversible HER1 and HER2 inhibitor that has demonstrated anti-tumor activity in vivo in patients with HER2+ $\mathrm{GC}^{91,93}$. Clinical trials are assessing its efficacy in combination with trastuzumab and with cisplatin plus $5 \mathrm{FU}^{84}$.

\section{Pan-inhibitors (HER1/HER2/HER4)}

AST1306 is an orally active, highly selective and irreversible HER inhibitor with promising anticancer activity in patients with previously-treated, advanced solid tumors. Partial response was confirmed in 12.7\% of patients (among them, one with GC), and stable disease for $\geq 6$ months was observed in $12.7 \%$ of patients. AST1306 can potently inhibit the EGFR T790M mutation, which is commonly associated with acquired resistance to first-generation HER1 inhibitors in non-small cell lung cancer ${ }^{94}$.

Dacomitinib induces apoptosis and arrests the cell cycle in G1, and also inhibits signaling pathways phosphorylation and transduction in HER2+ GC cells. In addition, it blocks the formation of HER1/HER2, HER2/ HER3 and HER3/HER4 heterodimers. Synergy has been observed with many commonly employed cytotoxic agents (5FU, cisplatin, docetaxel and paclitaxel) and with targeted agents, such as trastuzumab ${ }^{95}$. Dacomitinib was used in patients with HER2+ advanced GC as single agent after failure of at least one previous chemotherapy regimen, but no substantial survival improvement was observed ${ }^{81}$ (Table 2). 
Poziotinib inhibits the phosphorylation of the HER family members and molecules of the signaling cascade. It also induces apoptosis and cell cycle arrest at phase G1. Although this agent was inactive as monotherapy in HER2- cell lines, synergy was reported in both HER2+ and HER- models ${ }^{96}$.

AZD8931 provides EGFR, HER2 and HER3-signaling inhibition. The efficacy of this drug in combination with paclitaxel was assessed in patients with advanced GC; however, the trial was prematurely stopped due to the low response observed ${ }^{84}$.

\section{Conclusions}

The conducted review allows observing that there is broad heterogeneity in molecular alterations such as overexpression and amplification in GC; somatic mutations are not common since, worldwide, only 88 different mutations have been reported in the four genes that encode the HER proteins.

Meanwhile, the treatments focused on improving the quality of life and prolonging survival in patients with advanced GC have not shown significant improvements in the past few years; therefore, further studies are required in order to identify the best options for the treatment of these patients. The fact that ethnic differences have been observed in the survival results in patients with other malignancies in response to the treatment with tyrosine kinase inhibitors and chemotherapy (which also were observed in cases of GC) is of great importance, and it should therefore be taken into account. Fortunately, a larger number of studies are currently considering the patients' molecular profile in the search for treatments, which may generate a better response to the drugs.

\section{Acknowledgements}

We thank Prof. Lourdes Carbajal for her support in the review of the manuscript.

\section{References}

1. Ferlay J, Soerjomataram I, Ervik M, et al. GLOBOCAN 2012 v1.0. Cancer incidence and mortality worldwide: IARC CancerBase No. 11. Lyon, France: International Agency for Research on Cancer; 2013. (Consultado el 18 de febrero de 2016.) Disponible en: http://globocan.iarc.fr

2. $\mathrm{Li} \mathrm{H}, \mathrm{Yu} \mathrm{B}, \mathrm{Li} \mathrm{J}$, et al. Characterization of differentially expressed genes involved in pathways associated with gastric cancer. PLoS One. 2015; 10:e0125013.

3. Roskoski R Jr. The ErbB/HER family of protein-tyrosine kinases and cancer. Pharmacol Res. 2014;79:34-74.

4. Gschwind A, Fischer OM, Ullrich A. The discovery of receptor tyrosine kinases: targets for cancer therapy. Nat Rev Cancer. 2004;4:361-70.

5. Hofmann M, Stoss O, Shi D, et al. Assessment of a HER2 scoring system for gastric cancer: results from a validation study. Histopathology. 2008;52:797-805
6. Begnami MD, Fukuda E, Fregnani JH, et al. Prognostic implications of altered human epidermal growth factor receptors (HERs) in gastric carcinomas: HER2 and HER3 are predictors of poor outcome. J Clin Oncol. 2011;29:3030-6.

7. Jácome AA, Wohnrath DR, Scapulatempo Neto C, et al. Prognostic value of epidermal growth factor receptors in gastric cancer: a survival analysis by Weibull model incorporating long-term survivors. Gastric Cancer. 2014;17:76-86.

8. Aydin K, Okutur SK, Bozkurt M, et al. Effect of epidermal growth factor receptor status on the outcomes of patients with metastatic gastric cancer: a pilot study. Oncol Lett. 2014;7:255-9.

9. Braut T, Krstulja M, Kujundzić M, et al. Epidermal growth factor receptor protein expression and gene amplification in normal, hyperplastic, and cancerous glottic tissue: immunohistochemical and fluorescent in situ hybridization study on tissue microarrays. Croat Med J. 2009:50:370-9.

10. Inokuchi M, Murayama T, Hayashi M, et al. Prognostic value of co-expression of STAT3, mTOR and EGFR in gastric cancer. Exp Ther Med. $2011 ; 2: 251-6$

11. Terashima M, Kitada K, Ochiai A, et al. Impact of expression of human epidermal growth factor receptors EGFR and ERBB2 on survival in stage II/III gastric cancer. Clin Cancer Res. 2012;18:5992-6000.

12. Atmaca A, Werner D, Pauligk $C$, et al. The prognostic impact of epidermal growth factor receptor in patients with metastatic gastric cancer. BMC Cancer. 2012;12:524

13. Matsubara J, Yamada Y, Hirashima Y, et al. Impact of insulin-like growth factor type 1 receptor, epidermal growth factor receptor, and HER2 expressions on outcomes of patients with gastric cancer. Clin Cancer Res. 2008; $14: 3022-9$.

14. Jørgensen JT, Hersom M. HER2 as a prognostic marker in gastric cancer - a systematic analysis of data from the literature. J Cancer. 2012; 3:137-44.

15. Choi MR, An $\mathrm{CH}$, Chung $\mathrm{YJ}$, et al. Mutational and expressional analysis of ERBB3 gene in common solid cancers. APMIS. 2014:122:1207-12.

16. He XX, Ding L, Lin $Y$, et al. Protein expression of HER2, 3, 4 in gastric cancer: correlation with clinical features and survival. J Clin Pathol. 2015; 68:374-80.

17. Yamashita K, Sakuramoto S, Watanabe M. Genomic and epigenetic profiles of gastric cancer: potential diagnostic and therapeutic applications. Surg Today. 2011;41:24-38.

18. Wu X, Chen $Y, \mathrm{Li} \mathrm{G}$, et al. Her3 is associated with poor survival of gastric adenocarcinoma: Her3 promotes proliferation, survival and migration of human gastric cancer mediated by PI3K/AKT signaling pathway. Med Oncol. 2014;31:903.

19. Hayashi M, Inokuchi M, Takagi $Y$, et al. High expression of HER3 is associated with a decreased survival in gastric cancer. Clin Cancer Res. 2008:14:7843-9.

20. Nielsen TO, Sorensen S, Dagnaes-Hansen F, et al. Directing HER4 mRNA expression towards the CYT2 isoform by antisense oligonucleotide decreases growth of breast cancer cells in vitro and in vivo. $\mathrm{Br} J$ Cancer. 2013;108:2291-8.

21. Kataoka $\mathrm{H}$, Joh $\mathrm{T}$, Kasugai $\mathrm{K}$, et al. Expression of mRNA for heregulin and its receptor, ErbB-3 and ErbB-4, in human upper gastrointestinal mucosa. Life Sci. 1998:63:553-64.

22. Wang YK, Gao CF, Yun T, et al. Assessment of ERBB2 and EGFR gene amplification and protein expression in gastric carcinoma by immunohistochemistry and fluorescence in situ hybridization. Mol Cytogenet. 2011;4:14

23. Moutinho $C$, Mateus AR, Milanezi $F$, et al. Epidermal growth factor receptor structural alterations in gastric cancer. BMC Cancer. 2008;8:10.

24. Tsugawa K, Yonemura $\mathrm{Y}$, Hirono $\mathrm{Y}$, et al. Amplification of the c-met, c-erbB-2 and epidermal growth factor receptor gene in human gastric cancers: correlation to clinical features. Oncology. 1998;55:475-81.

25. Luber B, Deplazes J, Keller G, et al. Biomarker analysis of cetuximab plus oxaliplatin/leucovorin/5-fluorouracil in first-line metastatic gastric and oesophago-gastric junction cancer: results from a phase II trial of the Arbeitsgemeinschaft Internistische Onkologie (AIO). BMC Cancer. 2011;11:509.

26. Takehana $\mathrm{T}$, Kunitomo $\mathrm{K}$, Kono $\mathrm{K}$, et al. Status of $\mathrm{c}$-erbB-2 in gastric adenocarcinoma: a comparative study of immunohistochemistry, fluorescence in situ hybridization and enzyme-linked immuno-sorbent assay. Int J Cancer. 2002;98:833-7

27. Tanner M, Hollmén M, Junttila TT, et al. Amplification of HER-2 in gastric carcinoma: association with topoisomerase Ilalpha gene amplification, intestinal type, poor prognosis and sensitivity to trastuzumab. Ann Oncol. 2005;16:273-8.

28. Park DI, Yun JW, Park JH, et al. HER-2/neu amplification is an independent prognostic factor in gastric cancer. Dig Dis Sci. 2006;51:1371-9.

29. Bang $\mathrm{Y}$, Chung $\mathrm{H}, \mathrm{Xu} \mathrm{J}$, et al. Pathological features of advanced gastric cancer (GC): relationship to human epidermal growth factor receptor 2 (HER2) positivity in the global screening programme of the ToGA trial. J Clin Oncol. 2009;27:15s.

30. Bang YJ, Van Cutsem E, Feyereislova A, et al. Trastuzumab in combination with chemotherapy versus chemotherapy alone for treatment of HER2-positive advanced gastric or gastro-oesophageal junction cancer (TOGA): a phase 3, open-label, randomised controlled trial. Lancet. 2010;376:687-97. 


\section{A.R. Bustos-Carpinteyro, et al.: HER receptors in gastric cancer}

31. Liu Z, Liu L, Li M, et al. Epidermal growth factor receptor mutation in gastric cancer. Pathology. 2011;43:234-8.

32. Abediankenari S, Jeivad F. Epidermal growth factor receptor gene polymorphisms and gastric cancer in Iran. Asian Pac J Cancer Prev. 2013; 14:3187-90.

33. Lee JW, Soung YH, Kim SY, et al. ERBB2 kinase domain mutation in a gastric cancer metastasis. APMIS. 2005;113:683-7.

34. Lee JW, Soung YH, Seo SH, et al. Somatic mutations of ERBB2 kinase domain in gastric, colorectal, and breast carcinomas. Clin Cancer Res. 2006;12:57-61.

35. Stephens $P$, Hunter $C$, Bignell G, et al. Lung cancer: intragenic ERBB2 kinase mutations in tumours. Nature. 2004:431:525-6.

36. Wang K, Kan J, Yuen ST, et al. Exome sequencing identifies frequent mutation of ARID1A in molecular subtypes of gastric cancer. Nat Genet. 2011;43:1219-23.

37. Soung YH, Lee JW, Kim SY, et al. Somatic mutations of the ERBB4 kinase domain in human cancers. Int J Cancer. 2006;118:1426-9.

38. Becker JC, Müller-Tidow C, Stolte M, et al. Acetylsalicylic acid enhances antiproliferative effects of the EGFR inhibitor gefitinib in the absence of activating mutations in gastric cancer. Int J Oncol. 2006;29:615-23.

39. Mammano E, Belluco C, Sciro M, et al. Epidermal growth factor receptor (EGFR): mutational and protein expression analysis in gastric cancer. Anticancer Res. 2006;26:3547-50.

40. Mimori K, Nagahara H, Sudo T, et al. The epidermal growth factor receptor gene sequence is highly conserved in primary gastric cancers. J Surg Oncol. 2006;93:44-6.

41. Xu Z, Huo X, Ye H, et al. Genetic mutation analysis of human gastric adenocarcinomas using ion torrent sequencing platform. PLoS One. 2014;9:e100442.

42. Forbes SA, Beare D, Gunasekaran P, et al. COSMIC: exploring the world's knowledge of somatic mutations in human cancer. Nucleic Acids Res. 2015;43(Database issue):D805-11.

43. Holbrook JD, Parker JS, Gallagher KT, et al. Deep sequencing of gastric carcinoma reveals somatic mutations relevant to personalized medicine. J Transl Med. 2011;9:119.

44. Jaiswal BS, Kljavin NM, Stawiski EW, et al. Oncogenic ERBB3 mutations in human cancers. Cancer Cell. 2013;23:603-17.

45. Bose R, Kavuri SM, Searleman AC, et al. Activating HER2 mutations in HER2 gene amplification negative breast cancer. Cancer Discov. 2013; 3:224-37

46. Yan M, Parker BA, Schwab R, et al. HER2 aberrations in cancer: implications for therapy. Cancer Treat Rev. 2014;40:770-80.

47. Lin WL, Kuo WH, Chen FL, et al. Identification of the coexisting HER2 gene amplification and novel mutations in the HER2 protein-overexpressed mucinous epithelial ovarian cancer. Ann Surg Oncol. 2011; 18:2388-94.

48. $\mathrm{Xu} \mathrm{Z}$, Huo X, Ye H, et al. Genetic mutation analysis of human gastric adenocarcinomas using ion torrent sequencing platform. PLoS One. 2014:9:e100442.

49. Martinelli E, De Palma R, Orditura M, et al. Anti-epidermal growth factor receptor monoclonal antibodies in cancer therapy. Clin Exp Immunol. 2009;158:1-9.

50. Saltz LB, Lenz HJ, Kindler HL, et al. Randomized phase II trial of cetuximab, bevacizumab, and irinotecan compared with cetuximab and bevacizumab alone in irinotecan-refractory colorectal cancer: the BOND-2 study. J Clin Oncol. 2007;25:4557-61.

51. Vermorken JB, Mesia R, Rivera F, et al. Platinum-based chemotherapy plus cetuximab in head and neck cancer. N Engl J Med. 2008; 359:1116-27.

52. Kim MA, Lee HJ, Yang HK, et al. Heterogeneous amplification of ERBB2 in primary lesions is responsible for the discordant ERBB2 status of primary and metastatic lesions in gastric carcinoma. Histopathology. 2011;59:822-31.

53. Morishita A, Gong J, Masaki T. Targeting receptor tyrosine kinases in gastric cancer. World J Gastroenterol. 2014;20:4536-45.

54. Kothari N, Almhanna K. Current status of novel agents in advanced gastroesophageal adenocarcinoma. J Gastrointest Oncol. 2015;6:60-74.

55. Pinto C, Di Fabio F, Barone C, et al. Phase II study of cetuximab in combination with FOLFIRI in patients with untreated advanced gastric or gastroesophageal junction adenocarcinoma (FOLCETUX study). Ann Oncol. 2007; 18:510-7.

56. Kanzler S, Trarbach T, Seufferlein T, et al. Cetuximab with irinotecan/ folinic acid/5FU as firstline treatment in advanced gastric cancer: a nonrandomized multicenter AIO phase II study. J Clin Oncol. 2009; $27: 15 \mathrm{~s}$

57. Moehler M, Mueller A, Trarbach T, et al. Cetuximab with irinotecan, folinic acid and 5-fluorouracil as first-line treatment in advanced gastroesophageal cancer: a prospective multi-center biomarker-oriented phase II study. Ann Oncol. 2011;22:1358-66.

58. Yeh $\mathrm{K}, \mathrm{Hsu} \mathrm{C}, \mathrm{Hsu} \mathrm{C}$, et al. Phase II study of cetuximab plus weekly cisplatin and 24hour infusion of highdose 5fluorouracil and leucovorin for the firstline treatment of advanced gastric cancer. J Clin Oncol. 2009;27:15s
59. Han SW, Oh DY, Im SA, et al. Phase II study and biomarker analysis of cetuximab combined with modified FOLFOX6 in advanced gastric cancer. Br J Cancer. 2009;100:298-304.

60. Richards D, Kocs DM, Spira Al, et al. Results of docetaxel plus oxaliplatin $(\mathrm{DOCOX}) \pm$ cetuximab in patients with metastatic gastric and/or gastroesophageal junction adenocarcinoma: results of a randomised phase 2 study. Eur J Cancer. 2013;49:2823-31.

61. Pinto C, Di Fabio F, Barone C, et al. Phase II study of cetuximab in combination with cisplatin and docetaxel in patients with untreated advanced gastric or gastro-oesophageal junction adenocarcinoma (DOCETUX study). Br J Cancer. 2009;101:1261-8.

62. Lordick F, Kang YK, Chung HC, et al. Capecitabine and cisplatin with or without cetuximab for patients with previously untreated advanced gastric cancer (EXPAND): a randomised, open-label phase 3 trial. Lancet Oncol. 2013;14:490-9.

63. Li J, Liu X, Wang BY, et al. Phase II study of cetuximab in combination with modified FOLFIRI in patients with advanced gastric cancer who failed firstline chemotherapy (EFFI study). Clin Oncol. 2010;28:15s.

64. Schønnemann KR, Yilmaz M, Bjerregaard JK, et al. Phase II study of biweekly cetuximab in combination with irinotecan as second-line treatment in patients with platinum-resistant gastro-oesophageal cancer. Eur J Cancer. 2012:48:510-7.

65. Park SR, Kook MC, Choi IJ, et al. Predictive factors for the efficacy of cetuximab plus chemotherapy as salvage therapy in metastatic gastric cancer patients. Cancer Chemother Pharmacol. 2010;65:579-87.

66. Tebbutt NC, Parry MM, Zannino D, et al. Docetaxel plus cetuximab as second-line treatment for docetaxel-refractory oesophagogastric cancer: the AGITG ATTAX2 trial. Br J Cancer. 2013;108:771-4.

67. Chan JA, Blaszkowsky LS, Enzinger PC, et al. A multicenter phase II trial of single-agent cetuximab in advanced esophageal and gastric adenocarcinoma. Ann Oncol. 2011;22:1367-73.

68. Waddell T, Chau I, Cunningham D, et al. Epirubicin, oxaliplatin, and capecitabine with or without panitumumab for patients with previously untreated advanced oesophagogastric cancer (REAL3): a randomised, open-label phase 3 trial. Lancet Oncol. 2013;14:481-9.

69. Rao S, Starling N, Cunningham D, et al. Matuzumab plus epirubicin, cisplatin and capecitabine (ECX) compared with epirubicin, cisplatin and capecitabine alone as first-line treatment in patients with advanced oesophago-gastric cancer: a randomised, multicentre open-label phase II study. Ann Oncol. 2010;21:2213-9.

70. Wang JW, Chi Y, Zheng ZX, et al. Randomized, singlecentered, phase II clinical trial of nimotuzumab plus cisplatin and S1 as first line therapy in patients with advanced gastric cancer. J Clin Oncol. 2012;30(Suppl):e14668.

71. Satoh T, Lee KH, Rha SY, et al. Randomized phase II trial of nimotuzumab plus irinotecan versus irinotecan alone as second-line therapy for patients with advanced gastric cancer. Gastric Cancer. 2015; 18;824-32.

72. Xu CD. Clinical study of nimotuzumab combined with chemotherapy in the treatment of late stage gastric cancer. Asian Pac J Cancer Prev. 2014;15:10273-6.

73. Dragovich T, McCoy S, Fenoglio-Preiser CM, et al. Phase II trial of erlotinib in gastroesophageal junction and gastric adenocarcinomas: SWOG 0127. J Clin Oncol. 2006;24:4922-7.

74. Wainberg ZA, Lin LS, DiCarlo B, et al. Phase II trial of modified FOLFOX6 and erlotinib in patients with metastatic or advanced adenocarcinoma of the oesophagus and gastro-oesophageal junction. $\mathrm{Br} \mathrm{J}$ Cancer. 2011;105:760-5

75. Adelstein DJ, Rodríguez CP, Rybicki LA, et al. A phase II trial of gefitinib for recurrent or metastatic cancer of the esophagus or gastroesophageal junction. Invest New Drugs. 2012;30:1684-9.

76. Rodríguez CP, Adelstein DJ, Rice TW, et al. A phase II study of perioperative concurrent chemotherapy, gefitinib, and hyperfractionated radiation followed by maintenance gefitinib in locoregionally advanced esophagus and gastroesophageal junction cancer. J Thorac Oncol. 2010;5:229-35.

77. Iqbal S, Goldman B, Fenoglio-Preiser CM, et al. Southwest Oncology Group study S0413: a phase II trial of lapatinib (GW572016) as first-line therapy in patients with advanced or metastatic gastric cancer. Ann Oncol. 2011:22:2610-5.

78. Lorenzen S, Riera Knorrenschild J, Haag GM, et al. Lapatinib versus lapatinib plus capecitabine as second-line treatment in human epidermal growth factor receptor 2-amplified metastatic gastro-oesophageal cancer: a randomised phase II trial of the Arbeitsgemeinschaft Internistische Onkologie. Eur J Cancer. 2015;51:569-76.

79. Hecht JR, Bang YJ, Qin S, et al. Lapatinib in combination with capecitabine plus oxaliplatin (CapeOx) in HER2-positive advanced or metastatic gastric, esophageal, or gastroesophageal adenocarcinoma (AC): the TRIO-013/LOGiC trial. J Clin Oncol. 2013;31(Suppl):LBA4001.

80. Satoh T, Xu RH, Chung HC, et al. Lapatinib plus paclitaxel versus paclitaxel alone in the second-line treatment of HER2-amplified advanced gastric cancer in Asian populations: TyTAN - a randomized, phase III study. J Clin Oncol. 2014;32:2039-49. 
81. Lee KH, Oh DY, Lee KW, et al. A phase II open label trial of PF-00299804 monotherapy in patients with HER-2 positive advanced gastric cance after failure of at least one prior chemotherapy regimen. Ann Oncol. 2012;23(Suppl 11):xi19-20.

82. Adua D, Di Fabio F, Rojas Llimpe FL, et al. Long-term survival in an advanced gastric cancer patient treated with cetuximab in association with FOLFIRI: a case report. J Gastrointest Oncol. 2014;5:E13-7.

83. Gibson TB, Ranganathan A, Grothey A. Randomized phase III trial results of panitumumab, a fully human anti-epidermal growth factor receptor monoclonal antibody, in metastatic colorectal cancer. Clin Colorecta Cancer. 2006:6:29-31.

84. ClinicalTrials.gov. Bethesda (MD): National Library of Medicine (US) 2000-2015. (Consultado el 5 de julio de 2016.) Disponible en: https:// clinicaltrials.gov.

85. Luo $\mathrm{HQ}$, Han L, Jiang $Y$. Meta-analysis of six randomized control trials of chemotherapy plus anti-HER monoclonal antibody for advanced gastric and gastroesophageal cancer. Asian Pac J Cancer Prev. 2014; 15:5343-8.

86. Seidman A, Hudis C, Pierri MK, et al. Cardiac dysfunction in the trastuzumab clinical trials experience. J Clin Oncol. 2002;20:1215-21.

87. Ewer MS, Vooletich MT, Durand JB, et al. Reversibility of trastuzumab-related cardiotoxicity: new insights based on clinical course and response to medical treatment. J Clin Oncol. 2005;23:7820-6.

88. Ayyappan S, Prabhakar D, Sharma N. Epidermal growth factor receptor (EGFR)-targeted therapies in esophagogastric cancer. Anticancer Res. 2013:33:4139-55.
89. Franklin MC, Carey KD, Vajdos FF, et al. Insights into ErbB signaling from the structure of the ErbB2-pertuzumab complex. Cancer Cell. 2004;5:317-28.

90. Ballantyne A, Dhillon S. Trastuzumab emtansine: first global approval. Drugs. 2013;73:755-65.

91. Moorcraft SY, Chau I. Investigational therapies targeting the ErbB family in oesophagogastric cancer. Expert Opin Investig Drugs. 2014; 23:1349-63.

92. McDonagh CF, Huhalov A, Harms BD, et al. Antitumor activity of a novel bispecific antibody that targets the ErbB2/ErbB3 oncogenic unit and inhibits heregulin-induced activation of ErbB3. Mol Cancer Ther. 2012;11:582-93.

93. Janjigian $\mathrm{YY}$, Viola-Villegas $\mathrm{N}$, Holland JP, et al. Monitoring afatinib treatment in HER2-positive gastric cancer with 18F-FDG and 89Zr-trastuzumab PET. J Nucl Med. 2013;54:936-43.

94. Zhang J, Cao J, Li J, et al. A phase I study of AST1306, a novel irreversible EGFR and HER2 kinase inhibitor, in patients with advanced solid tumors. J Hematol Oncol. 2014;7:22.

95. Nam HJ, Ching KA, Kan J, et al. Evaluation of the antitumor effects and mechanisms of PF00299804, a pan-HER inhibitor, alone or in combination with chemotherapy or targeted agents in gastric cancer. Mol Cancer Ther. 2012;11:439-51.

96. Nam HJ, Kim HP, Yoon YK, et al. Antitumor activity of HM781-36B, an irreversible Pan-HER inhibitor, alone or in combination with cytotoxic chemotherapeutic agents in gastric cancer. Cancer Lett. 2011;302:155-65. 